\title{
marges Marges
}

revue d'art contemporain Revue d'art contemporain

12 | 2011

Exposition sans artiste(s)

\section{Geste serpentine et autres prophéties}

FRAC Lorraine, 15 janvier - $1^{\mathrm{er}}$ mai 2011

\section{Camille Paulhan}

\section{(2) OpenEdition}

\section{Journals}

Édition électronique

URL : http://journals.openedition.org/marges/428

DOI : $10.4000 /$ marges. 428

ISSN : 2416-8742

Éditeur

Presses universitaires de Vincennes

\section{Édition imprimée}

Date de publication : 15 avril 2011

Pagination : 136-137

ISBN : 978-2-84292-271-9

ISSN : 1767-7114

Référence électronique

Camille Paulhan, «Geste serpentine et autres prophéties », Marges [En ligne], 12 | 2011, mis en ligne le 15 avril 2011, consulté le 22 septembre 2020. URL : http://journals.openedition.org/marges/428 ;

DOI : https://doi.org/10.4000/marges.428 


\section{Geste serpentine et autres prophéties}

FRAC Lorraine

15 janvier $-1^{\text {er }}$ mai 2011

Raconter des histoires au lieu de raconter l'Histoire: voilà peut-être ce qui aura servi de point de départ à la constitution de l'exposition qui se au FRAC Lorraine. S'il est aujourd'hui courant de s'intéresser au pessimisme ambiant, à la pollution, au terrorisme, etc., il est également salutaire de voir vagabonder d'autres voies, s'engageant dans le conte ou la rêverie pour aborder des sujets graves. En guise de prologue à l'exposition, il avait ainsi été choisi de diffuser le film Leçons de ténèbres de Werner Herzog, documentaire prenant la forme d'un conte cruel: ici, les enfants pleurent des larmes de pétrole et les paysages fondent sous l'action de la chaleur, faisant miroiter leurs étendues désertes dans des lacs gluants d'huile. À l'encontre d'une approche journalistique de la Guerre du Golfe, le réalisateur avait préféré narrer une nouvelle apocalypse tout en s'extrayant du temps présent (le titre faisant référence à une liturgie catholique bien particulière, évoquant la destruction de Jérusalem).

Mais la force de l'exposition, à la suite d'une telle introduction, à la fois terrifiante et merveilleuse, est de ne pas s'enliser dans la démonstration, la référence historique ou la grandiloquence. Si son sujet principal est le temps, et la sensation d'accélération que la période contemporaine semble subir, il s'agirait plutôt ici d'un temps qui se replie sur luimême et décide de ne plus avancer. La mé- taphore du fil d'Ariane, qui ne sert plus à retrouver son chemin mais qui revient constamment sur lui-même au cœur d'un labyrinthe invisible, relie certaines œuvres entre elles: ainsi l'installation de Pierre-Étienne Morelle, où une pelote compacte de lanières de caoutchouc déplie dans la cour du bâtiment ses résidus, les faisant se recouvrir sans que l'extrémité de cette ligne de plusieurs kilomètres ne devienne visible. De la même manière, il est également question de labyrinthe avec Firmament III d'Antony Gormley, structure alvéolaire métallique semblant reproduire une voûte étoilée en trois dimensions. Si l'œuvre peut paraître au premier abord entièrement pénétrable, comme des bulles de bain moussant qui se seraient métamorphosées en acier, elle ne comporte en fait qu'une seule entrée adaptée au corps humain. Mais le plus important est peut-être ce qui sous-tend la pièce: cette matrice nébuleuse reproduirait un corps en position fœtale (mais bien astucieux serait le visiteur capable de le décrypter). Dès lors, et quand bien même il ne s'agirait que d'une fiction, il n'est plus question de l'immensité inquiétante d'un inconnu stellaire mais bien d'un cocon protecteur qui enveloppe la déambulation du spectateur.

Par ailleurs, la référence à l'histoire contemporaine ne s'inscrit qu'en filigrane dans les différentes œuvres: ainsi l'implosion possible du soleil est délicatement évoquée 
par Benoît Billotte, dont l'œuvre Sunline se présente comme une ardoise sur laquelle ont été tracées des courbes sinusoïdales qui évoqueraient l'activité des taches solaires. Le recours à de réelles données chiffrées sur ce phénomène est cependant estompé par le fait que les abscisses et ordonnées ont disparu, de même que toute explication scientifique à leur sujet. Ne persistent que des polygraphies, qui pourraient tout aussi bien évoquer la respiration légèrement tremblante et irrégulière d'un individu. L'œuvre de Monika Grzymala, sans pour autant l'affirmer, semble reproduire en ruban adhésif des images de carcasses métalliques liées au 11 septembre. Quant à Pratchaya Phinthong, il décide d'exploiter les peurs et autres fantasmes qui ne manquent pas de peupler Internet. 2017, texte alarmiste évoquant des expériences secrètes menées par les scientifiques du CERN, pourrait très bien n'être qu'un conte imaginé par l'artiste (le texte en question n'apparaissant sur aucun moteur de recherche). Car c'est bien de cela qu'il s'agit: les œuvres comme métaphores, et non comme retranscriptions littérales et triviales de notre monde contemporain.

Ici, le grandiose s'efface devant la fragilité: une œuvre s'évanouit au fur et à mesure de l'exposition, une autre menace à chaque entrée de visiteur de s'estomper sous un doigt trop curieux, une dernière ne daigne apparaître qu'à la lumière du soleil. C'est enfin sur le soleil négatif de Corey McCorkle qu'il faudrait clore cette exposition, les lignes d'horizon frémissantes d'Iñaki Bonillas et, plus éthérés que des images, les mots de lan Wilson, qui n'existent que par transmission orale et posent comme pour fermer la boucle cette ultime question: «Qu'est-ce que le temps?».

\section{Camille Paulhan}

